Family Profile No. 21, 2021

\title{
Stepfamilies among Currently Cohabiting and Married Women Under 45, 1988 and 2017
}

\section{Author: Karen B. Guzzo}

Changes in the stability of cohabiting and marital unions, combined with changes in nonmarital childbearing, means many of today's unions result in the formation of stepfamilies - unions in which one or both partners have a child from a previous relationship, regardless of whether those children live in the household. This profile combines new NCFMR analyses of the 20152019 National Survey of Family Growth (NSFG) data with published analyses of 1988 NSFG data (Guzzo, 2017), focusing on women under age 45 who lived with a partner (married or cohabiting) at the time of the survey. It examines shifts in the share of unions that are stepfamilies, shifts in the share of stepfamilies that are marriages versus cohabitations, and shifts in which partner has children from a past relationship (i.e., whether the female partner, male partner, or both have a child from a prior union). The 2015-2019 NSFG data represents the year 2017 when weighted.

\section{Shifts in the Share of Stepfamily Unions}

- In 1988, one in four coresidential unions among women under age 45 was a stepfamily. By 2017, this number had increased to one in three.

- The share of unions that were stepfamilies varied across union type.

○ Just under half of all currently cohabiting women were in a stepfamily at both time points.

- The percentage of marriages that were stepfamilies rose from $21 \%$ in 1988 to $27 \%$ in 2017.

Figure 1. Share of Current Cohabitations and Marriages That Are Stepfamilies

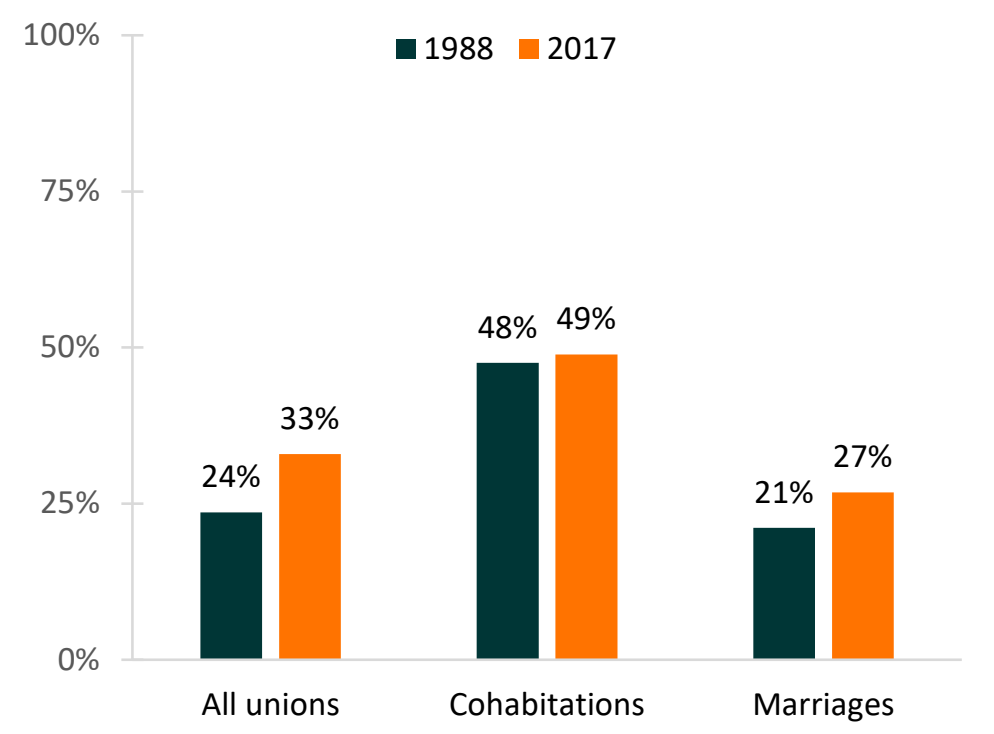

Source: 1988 (Guzzo, 2017); 2017: NCFMR analyses of the 20152019 NSFG, weighted to represent 2017

Shifts in the Share of Stepfamilies That Are Marriages vs. Cohabitations

Figure 2. Share of Current Stepfamily Unions Comprised of Marriages and Cohabitations

1988

2017
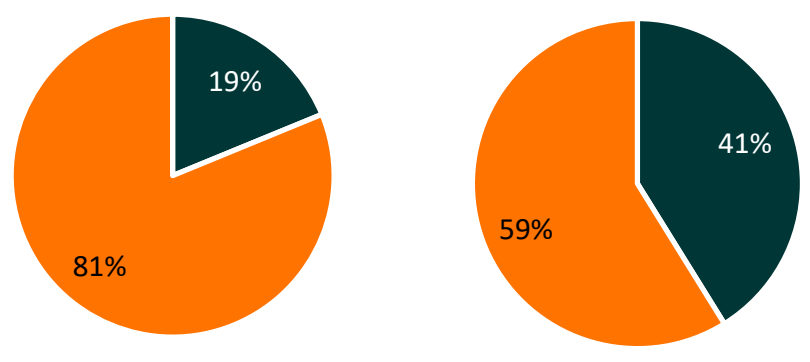

- As cohabiting unions have become more common, the share of stepfamilies comprised of cohabiting unions relative to marriages has increased.

○ In 1988, two in ten stepfamilies among women under age 45 were cohabitations.

- By 2017, the share doubled - four in ten stepfamilies among women under 45 were cohabitations. 


\section{Shifts in Stepparent Composition among Stepfamilies}

- In 1988, the share of all stepfamily unions among women under age 45 in which only the female partner had a child from a prior relationship was $50 \%$, with only the male partner having a child at $29 \%$, and $22 \%$ involved children from both partners' prior relationships.

- The biggest change in stepparent composition among all stepfamily unions was the share in which both partners had a child from a previous relationship, increasing from just under one-quarter in 1988 to just over one third in 2017. This represents a 1.6-fold increase.

- In both time periods, the share of stepfamily unions in which both partners had a child from a prior relationship was higher for cohabitations than marriages.

- Among cohabiting stepfamilies, four in ten included children from both partners' prior relationships in 2017; this was the most common stepparent composition.

- Among marital stepfamilies, three in ten included children from both partners' prior relationships in 2017, but the most common category was for only the female partner to have a child, at $37 \%$.

Figure 3. Stepparent Composition by Union Status

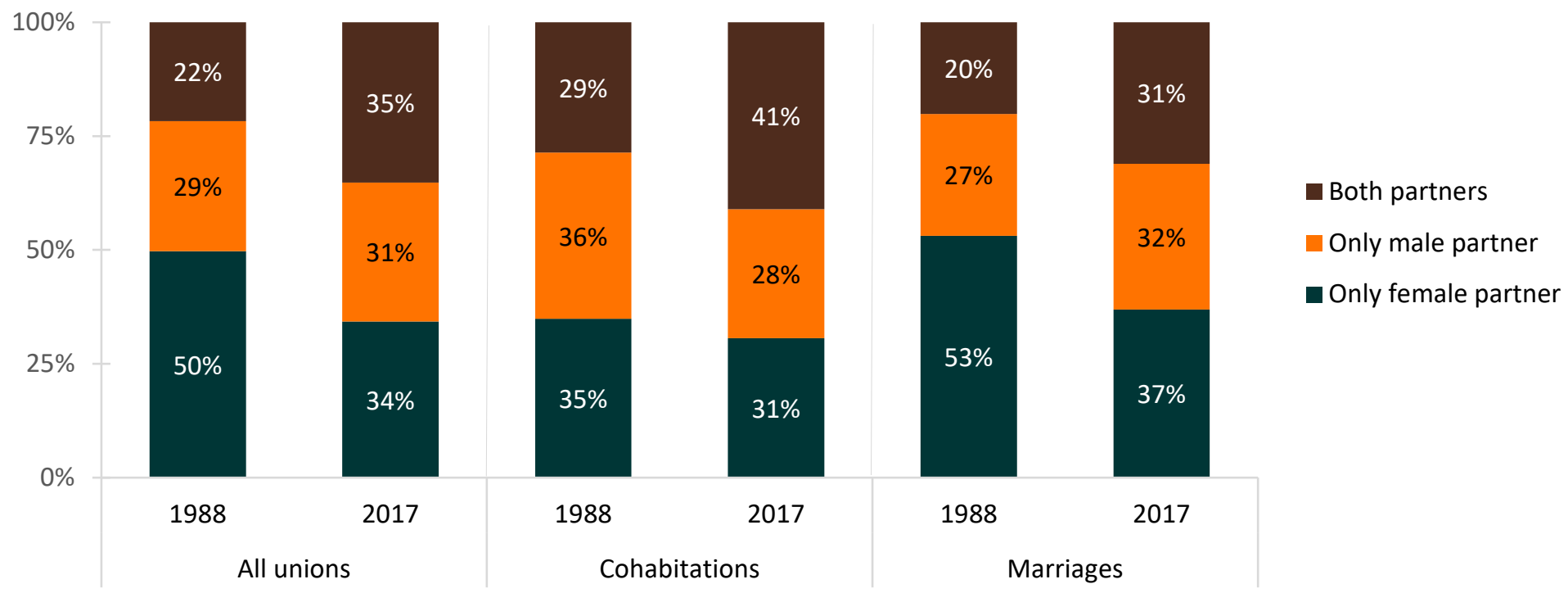

Source: 1988 (Guzzo, 2017); 2017: NCFMR analyses of the 2015-2019 NSFG, weighted to represent 2017

\section{In both time periods, the share of stepfamily unions in which both partners had a child from a prior relationship was higher for cohabitations than marriages.}

\section{Data Sources:}

National Center for Health Statistics (NCHS). National Survey of Family Growth Public-Use Data and Documentation. Hyattsville, MD: CDC National Center for Health Statistics. https://www.cdc.gov/nchs/nsfg/index.htm

\section{References:}

Guzzo, K. B. (2017). Shifts in higher-order unions and stepfamilies among currently cohabiting and married women of childbearing age. Journal of Family Issues, 38(12), 1775-1799.

\section{Suggested Citation:}

Guzzo, K. B. (2021). Stepfamilies among currently cohabiting and married women under 45, 1988 and 2017. Family Profiles, FP-2121. Bowling Green, OH: National Center for Family \& Marriage Research. https://doi.org/10.25035/ncfmr/fp-21-21 